\title{
Model predictive control and improved low-pass filtering strategies based on wind power fluctuation mitigation
}

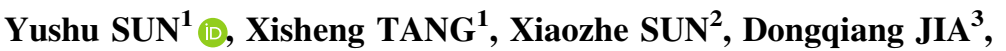 \\ Zhihuang $\mathrm{CAO}^{4}$, Jing $\mathrm{PAN}^{4}$, Bin $\mathrm{XU}^{4}$
}

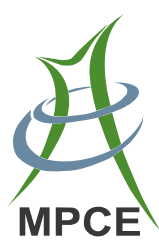

\begin{abstract}
The rapid development of renewable energy sources such as wind power has brought great challenges to the power grid. Wind power penetration can be improved by using hybrid energy storage (ES) to mitigate wind power fluctuation. We studied the strategy of smoothing wind power fluctuation and the strategy of hybrid ES power distribution. Firstly, an effective control strategy can be extracted by comparing constant-time low-pass filtering (CLF), variable-time low-pass filtering (VLF), wavelet packet decomposition (WPD), empirical mode decomposition (EMD) and model predictive control algorithms with fluctuation rate constraints of the identical grid-connected wind power. Moreover, the mean frequency of ES as the cutoff frequency can be acquired by the Hilbert Huang transform (HHT), and the time constant of filtering algorithm can be obtained. Then, an improved low-pass filtering algorithm (ILFA) is proposed to achieve the power allocation between lithium battery (LB) and supercapacitor (SC), which
\end{abstract}

CrossCheck date: 12 September 2018

Received: 12 March 2018 / Accepted: 12 September 2018 / Published
online: 26 December 2018
@ The Author(s) 2018
Yushu SUN
yushusun@mail.iee.ac.cn
Xisheng TANG
tang@mail.iee.ac.cn
Xiaozhe SUN
Tarim_sun@ $163 . c o m$
Dongqiang JIA
Jdq0202@126.com
Zhihuang CAO
caozh557x@ah.sgcc.com.cn
Jing PAN
panj0621@ah.sgcc.com.cn can overcome the over-charge and over-discharge of ES in the traditional low-pass filtering algorithm (TLFA). In addition, the optimized LB and SC power are further obtained based on the SC priority control strategy combined with the fuzzy control (FC) method. Finally, simulation results show that wind power fluctuation can be effectively suppressed by LB and SC based on the proposed control strategies, which is beneficial to the development of wind and storage system.

Keywords Wind power fluctuation mitigation, Control strategies, Model predictive control algorithm, Hybrid energy storage (ES), Improved low-pass filtering algorithm (ILFA), Fuzzy control (FC), Strategy

\section{Introduction}

As energy and environmental issues become increasingly prominent, renewable energy sources such as wind power have been rapidly developed. Large-scale grid-

Bin XU

xub0619@ah.sgcc.com.cn

Institute of Electrical Engineering, Chinese Academy of Sciences, Beijing 100190, China

2 Sinopec Oilfield Service Shengli Corporation Tarim Branch Company, Korla 841000, China

3 State Grid Beijing Electric Power Company Electric Power Research Institute, Beijing 100075, China

4 State Grid Anhui Electric Power Company, Hefei 230000, China 
connected renewable energy sources significantly affect the safe and stable operation of the power system owing to their randomness and intermittency [1-3]. Therefore, in order to enhance the penetration rate of grid-connected renewable energy sources, two methods are always used to improve their controllability. One method is to optimize the control of renewable energy sources and grid-connected interface devices. Reference [4] presents a technique for the control of a modular multilevel converter (MMC)-based distributed generation system in the gridconnected mode. Passivity-based controller, sliding mode method, and reference currents calculator are employed as the outer loop controller, central loop controller, and inner loop controller, respectively, to regulate the operation of an interfaced MMC under steady state operating conditions, and during load and parameter variations. Reference [5] describes a power-based control technique based on a double synchronous controller for an interfaced converter between the renewable energy sources and the power grid, including an active-reactive power-based dynamic equation, so that the stable operation of the power grid can be guaranteed during the integration of large-scale renewable energy sources. Reference [6] proposes a comprehensive dynamic model based on a direct quadrature rotating frame to control a grid-connected single-phase voltage source inverter combined with a capability curve based on active and reactive power. Reference [7] applies a synchronous active proportional resonant-based control technique for interfaced converters to improve the stable operation of the power grid under high penetration of distributed generation sources.

The other method is to size the energy storage (ES) system to reduce the impact of renewable energy power fluctuation on the grid. Reference [8] proposes a new model-driven controller that incorporates a battery ES system (BESS) into a voltage regulation scheme in order to counteract voltage variation caused by photovoltaic (PV) power fluctuations. Reference [9] investigates the effect of wind energy penetration on the frequency response of a multi-machine power network considering the different time constants of a low-pass filter in the direct current (DC) chopper of an energy capacitor system. The results show that a higher time constant of the low-pass filter effectively damps the oscillations of the grid variables and quickly restores the system during network disturbance. Reference [10] proposes the coordinated control strategy of a hybrid ES system (HESS) with complementary features to improve the accommodating ability of PV. Reference [11] illustrates an analytical formulation for assessing the reliability impact of ES supporting distributed generation in the supply restoration of isolated network areas.

Nowadays, using ES to smooth renewable energy power fluctuation has drawn more and more attention, and the corresponding control strategies are becoming more and more diverse. They include constant-time low-pass filtering (CLF), variable-time low-pass filtering (VLF), wavelet packet decomposition (WPD), empirical mode decomposition (EMD) and model predictive control (MPC) algorithms. In [12], because the power generation of PV and the load demand fluctuate frequently, a thirdorder Butterworth low-pass filter and high-pass filter are adopted to smooth the wind power and allocate power between the battery and supercapacitor (SC), where the time constant does not change. In [13], the aim of integrated HESS is to smooth the variations in wind-solar power production and ensure a more controllable output power based on CLF. CLF has the advantages of simplicity, reliability, and practicality. However, the time constant cannot be flexibly adjusted. Furthermore, renewable energy power is over-suppressed easily, which will increase the cost of ES.

The low-pass filter passes the lower components of the frequency of wind power. It shows that the wind power fluctuation decreases as the time constant of low-pass filter increases [14]. In order to improve the ability of power systems for integrating wind power, wind farm power output fluctuation is mitigated by an ES system with the control strategy of a flexible first-order low-pass filter control strategy. And the wind power is flat after smoothing [15]. A flexible first-order low-pass filter with an optimization of the time constant is developed to limit wind power fluctuation under restriction with smaller BESS capacity [16]. However, VLF has the defect in time delay due to its filtering properties, which is not conducive to online real-time control.

An HESS power allocation control including an online wavelet filter and a new power allocation optimization algorithm is adopted to meet the technical requirements of the grid for smoothing wind power. The online wavelet filtering method is established to minimize the phase lag in decomposing frequency components [17]. A new smoothing method based on self-adaptive WPD in HESS is proposed. It can adjust the wavelet decomposition level based on the change range of PV output power, so that the low frequency component of PV power can be accurately extracted [18]. A wind power filtering approach is presented to mitigate short- and long-term fluctuations using an HESS, and a new wavelet-based capacity configuration algorithm to properly size the HESS [19]. The power allocation between multi-type ES can be online achieved with WPD or wavelet decomposition. However, a large amount of historical data must be analyzed to select the wavelet function.

Wind power smoothing is achieved by regulating the output power of SCs and batteries to negate the high and low frequency fluctuating power components based on 
EMD [20]. The EMD is used to analyze the wind power fluctuations and the power distribution of the ES system. Different types of power commands can be obtained according to the reconstructed frequency characteristics, which are suitable for different types of ES systems [21]. EMD is used to smooth wind power fluctuation with a BESS. After describing the wind power, the low-frequency parts are used as the wind power grid-connected value, and the high-frequency parts are stored in the BESS [22]. Unfortunately, the decomposition results sometimes vary greatly owing to its broad cut-off conditions.

MPC is suitable for online optimization control with the advantage of high-precision model prediction and receding horizon optimization. In [23], a new coordinated control strategy based on MPC is proposed for wind power fluctuation suppression, which employs MPC for the total power required for the entire ES system.

In this paper, the schematic overview is shown in Fig. 1. In the figure, LB stands for lithium battery power, ILFA stands for improved low-pass filtering algorithm, and FC stands for fuzzy control.

The major contributions of this study are as follows.

1) Firstly, the impact of different smoothing strategies on wind power are analyzed. The optimal control strategy is selected for comparison with CLF, VLF, WPD, EMD and MPC. Then the reason is interpreted by the cut-off frequency analysis.

2) In addition, an ILFA is applied to achieve power allocation and to overcome the over-charge and overdischarge of hybrid ES compared with conventional low-pass filtering algorithm, whose time constant is flexibly obtained by Hilbert Huang transform (HHT). The optimized LB and SC power are further acquired, and the operation of hybrid energy is improved by the proposed SC priority FC-based control strategy.

This paper is organized as follows. The introduction is provided in Section 1. In Section 2, wind power fluctuation smoothing strategies are discussed in detail. In Section 3, the achievement of power allocation in hybrid ES based on an ILFA is described. In Section 4, conclusions are drawn.

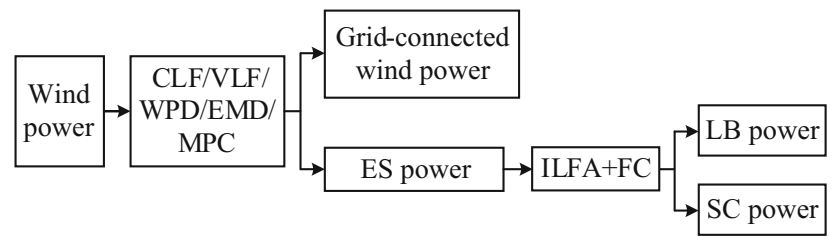

Fig. 1 Schematic overview

\section{Wind power fluctuation smoothing strategies}

A wind farm with installed capacity of $100 \mathrm{MW}$ is selected as the research object, whose sampling interval is $5 \mathrm{~s}$ and sampling time is $25000 \mathrm{~s}$. A 1-min grid-connected wind power fluctuation rate must be kept within $2 \%$ in this study. The control flowchart of wind power fluctuation mitigated by LB and SC is illustrated in Fig. 2.

1) According to grid-connected fluctuation rate constraints, wind power fluctuation is mitigated by a smoothing strategy, such as CLF, VLF, WPD, EMD, and MPC. ES power and grid-connected wind power can be obtained.

2) LB and SC power can be obtained by an improved low-pass filtering algorithm, whose time constant is calculated by HHT.

3) The SC power optimization is realized by FC based on the SC state of charge (SOC). Then, the optimized LB power can also be acquired.

\subsection{Low-pass filtering algorithm}

The schematic circuit of the low-pass filtering algorithm is introduced in Fig. 3. The relationship between output voltage $U_{y}$ and input voltage $U_{x}$ is described in (1).

$\tau \frac{\mathrm{d} Y}{\mathrm{~d} t}+Y=X$

where $\tau=R C$, and is the filter time constant; $R$ is the equivalent resistor; $C$ is the equivalent capacitor; $X$ denotes

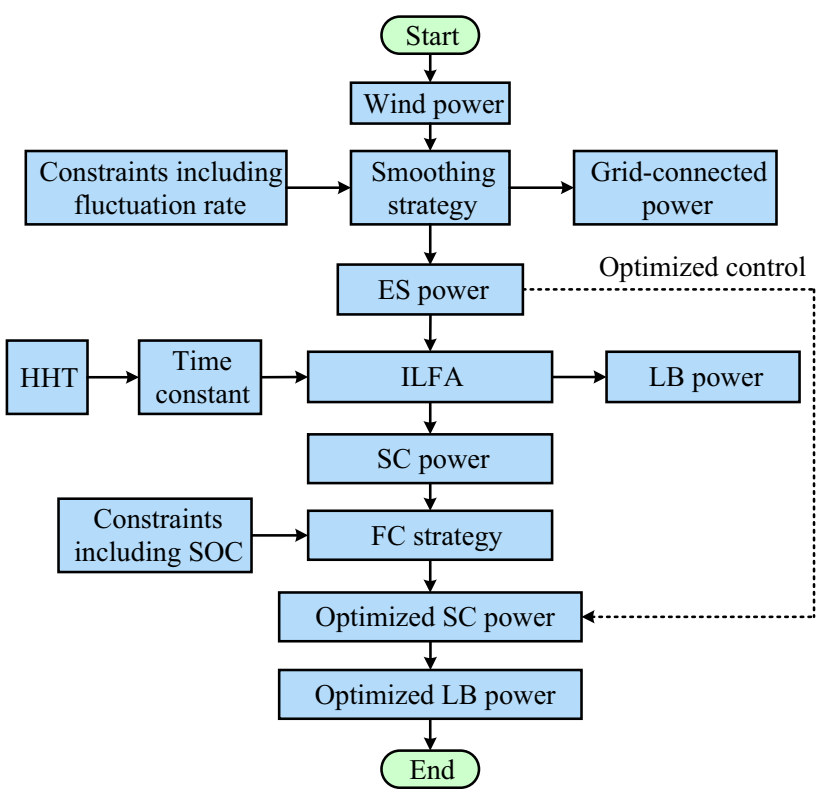

Fig. 2 Control flowchart of wind power fluctuation mitigation 


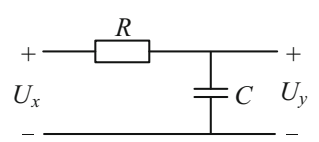

Fig. 3 Schematic circuit of a low-pass filtering algorithm

the original wind power is the input variable; $Y$ denotes the smoothed wind power is the output variable.

Suppose $T_{c}$ is the control step, equation (1) can be discretized as:

$\tau \frac{Y_{k}-Y_{k-1}}{T_{c}}+Y_{k}=X_{k}$

where $Y_{k}$ and $Y_{k-1}$ are the smoothed wind power at time $k$ and $k-1 ; X_{k}$ is the original wind power at time $k$.

The smoothed wind power $Y_{k}$ can be obtained by a transformation of (2).

$Y_{k}=\frac{\tau}{\tau+T_{c}} Y_{k-1}+\frac{T_{c}}{\tau+T_{c}} X_{k}$

Therefore, when wind power fluctuation is mitigated by the low-pass filtering algorithm, the low-frequency parts are the grid-connected wind power and the high-frequency parts are compensated by ES. In addition, the low-pass filtering algorithm can be divided into CLF and VLF depending on whether the filter time constant $\tau$ changes.

\subsubsection{CLF algorithm}

The frame diagram of wind power fluctuation mitigated by CLF is shown in Fig. 4. $P_{w}$ is the original wind power; $P_{g}$ is the grid-connected (smoothed) wind power; $P_{e s}$ is the ES power; $P_{e s, l i m}$ is the ES power limit; $\Delta P_{e s, \text { lim }}$ is the ES ramp power limit; and $S O C_{\lim }$ is the ES SOC limit.

The amplitude change in grid-connected wind power becomes smaller compared with that of the original wind power, which can be seen in Fig. 5. From Fig. 6, the 1-minute maximum (max) fluctuation rate of original wind power is 0.0630 , while that of the grid-connected wind power is 0.0180 . Therefore, the grid-connected wind power fluctuation rate is not greater than $2 \%$, which meets the grid requirements.

\subsubsection{VLF algorithm}

Wind power fluctuation is mitigated by VLF, and its frame diagram is shown in Fig. 7. The time constant of CLF is not changed in practical application, while that of VLF is dynamically adjusted by the change in the wind power fluctuation rate and ES SOC.

Wind power before and after smoothing by VLF is displayed in Fig. 8. The smoothed wind power fluctuation reduces. The 1-minute max fluctuation rate of smoothed

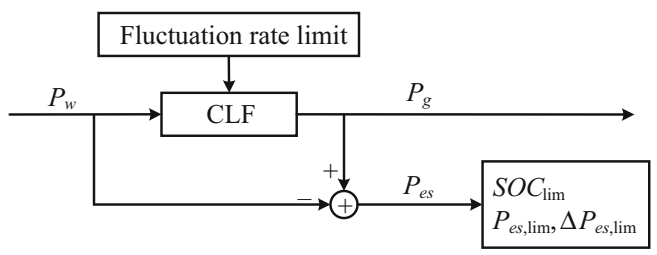

Fig. 4 CLF frame diagram

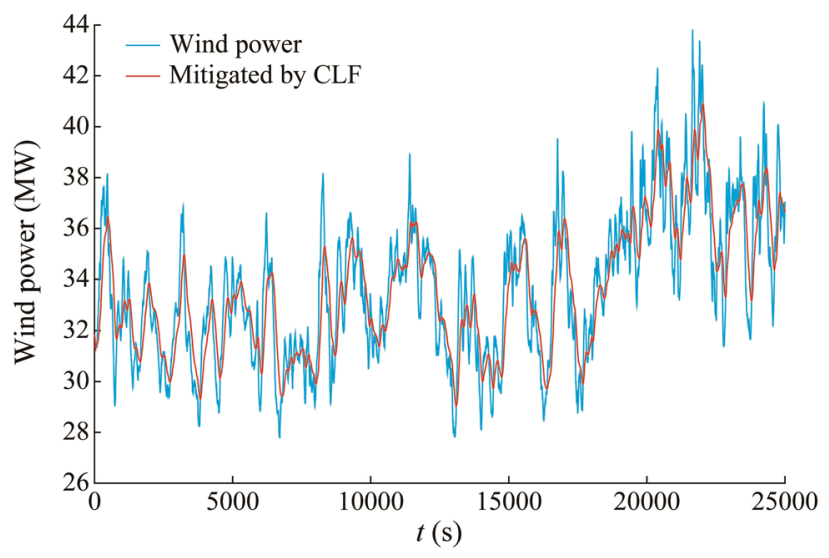

Fig. 5 Wind power before and after smoothing by CLF

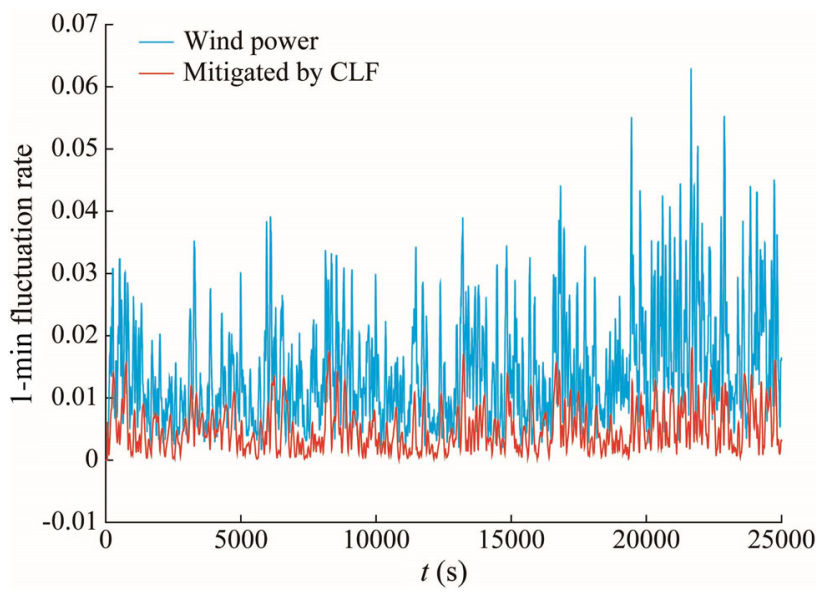

Fig. 6 Wind power fluctuation rate before and after smoothing by CLF

wind power is 0.0199, as shown in Fig. 9. This control strategy is of effectiveness.

\subsection{WPD algorithm}

WPD is developed based on a wavelet transform. It can map the signal to the $2^{j}$ wavelet package subspace. Then a complete binary tree structure is formed. The WPD frame diagram is shown in Fig. 10, where $\mathrm{W}$ is the wind power signal. 


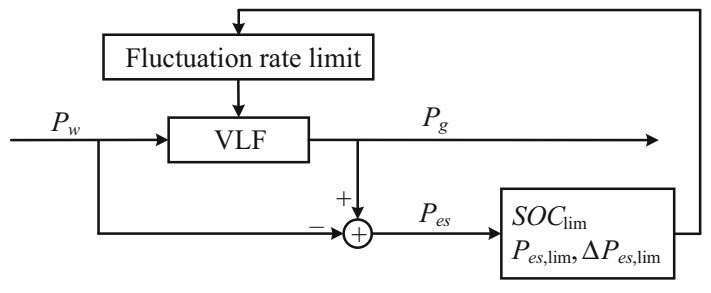

Fig. 7 VLF frame diagram

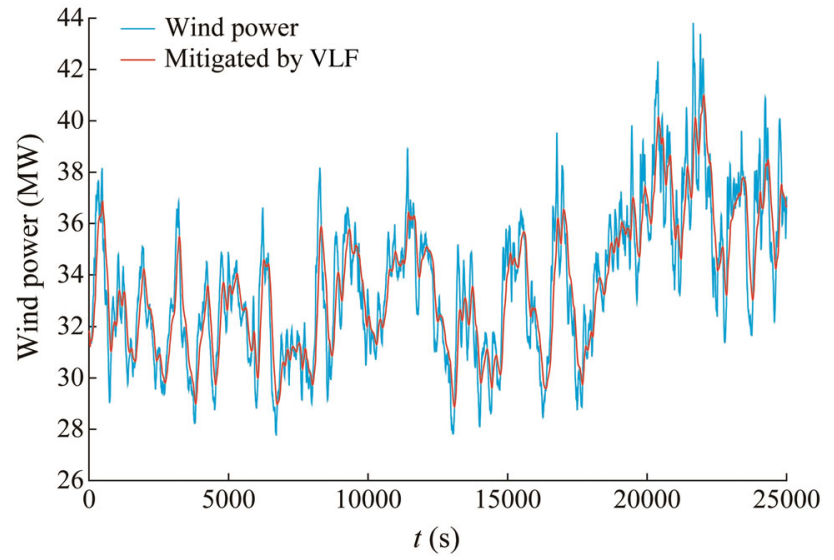

Fig. 8 Wind power before and after smoothing by VLF

The decomposition and reconstruction of the wind power signal is achieved based on a Dmeyer wavelet in this study. The bandwidth of each band is as follows.

$f_{0}=\frac{1}{t_{s}} \div 2 \div 2^{n}$

where $t_{s}$ is the sampling time; and $n$ is the number of layers in WPD. The first band frequency range is $0-f_{0}$, and the second one is $f_{0}-2 f_{0}$, etc.

The decomposition result of a 6-layer wavelet packet based on WPD is shown in Fig. 11. Wind power fluctuation

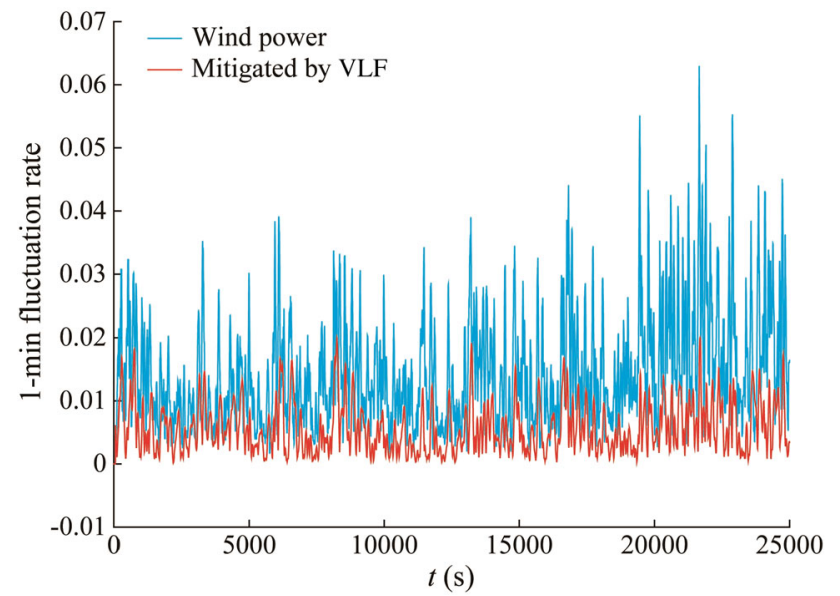

Fig. 9 Wind power fluctuation rate before and after smoothing by VLF

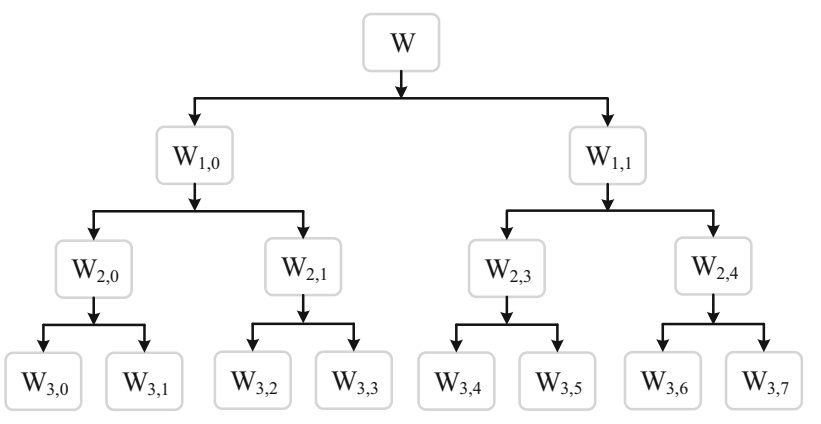

Fig. 10 WPD frame diagram

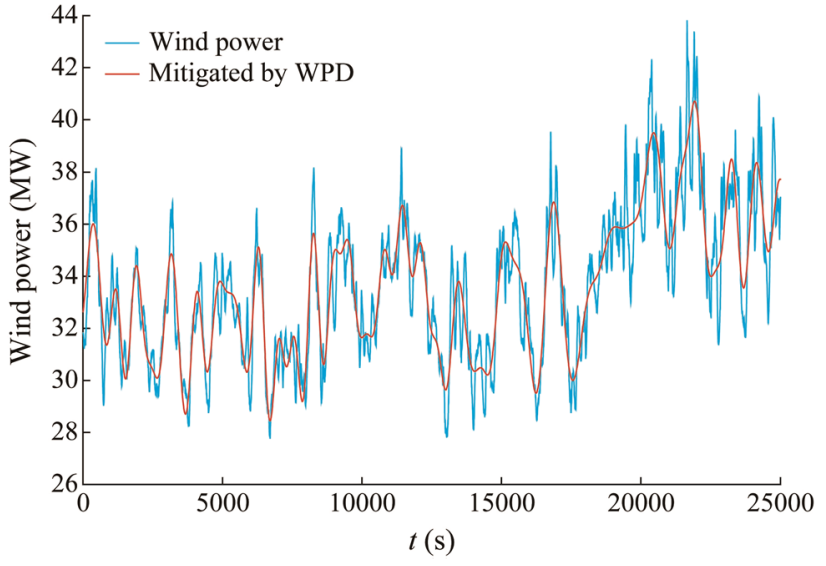

Fig. 11 Wind power before and after smoothing by WPD

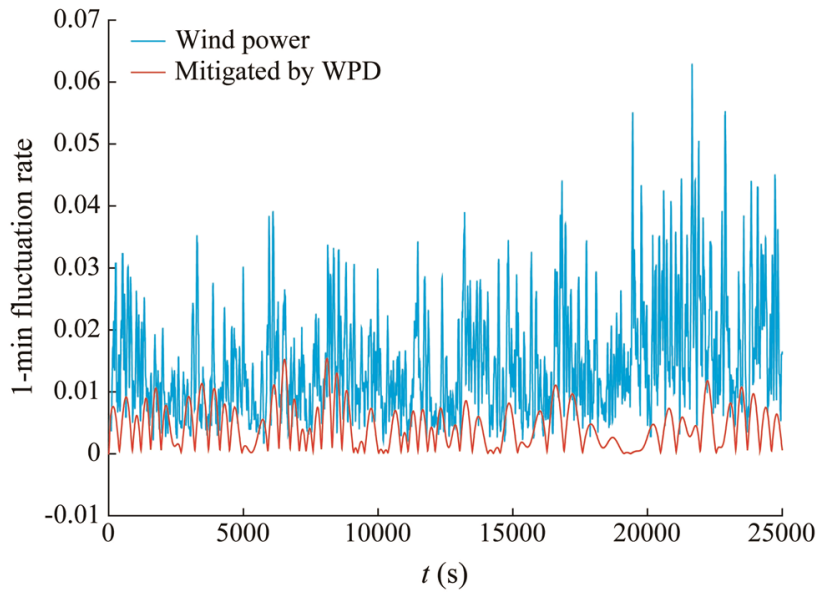

Fig. 12 Wind power fluctuation rate before and after smoothing by WPD

after smoothing is relatively small. For Fig. 12, the 1-minute max fluctuation rate of the smoothed wind power is 0.0154 , which can better meet the grid requirements.

\subsection{EMD algorithm}

1) EMD application 
A signal can be decomposed into a number of intrinsic mode function (IMF) components $c_{i}(i=1,2, \ldots, n)$ with the time axis symmetry and residue $r_{n}$. Each IMF must meet the following requirements: (1) in the entire data set, the number of extreme and zero-crossing points must equal or differ at most by one; and (2) at any point, the mean value of the envelope is zero. Decomposition will be stopped when one of the following things occur: (1) $c_{i}$ or $r_{n}$ is smaller than the prescribed value; and (2) $r_{n}$ becomes a monotonic function and IMF cannot be acquired. Therefore, the expression of signal $s(t)$ decomposed by EMD can be described as:

$s(t)=\sum_{i=1}^{n} c_{i}(t)+r_{n}$

\section{2) HHT application}

The original signal is decomposed into a series of IMFs by EMD, and HHT is applied to obtain the instantaneous amplitude and instantaneous frequency of the IMFs. For a continuous real signal $s(t)$, its HHT $s_{\mathrm{H}}(t)$ can be expressed as:

$s_{\mathrm{H}}(t)=\frac{1}{\pi} \int_{-\infty}^{+\infty} \frac{s(\sigma)}{t-\sigma} \mathrm{d} \sigma$

$s(t)$ is combined with $s_{\mathrm{H}}(t)$

$z(t)=s(t)+\mathrm{i} s_{\mathrm{H}}(t)=a(t) \mathrm{e}^{\mathrm{i} \varphi(\mathrm{t})}$

where $a(t)$ and $\varphi(t)$ are the instantaneous amplitude and instantaneous phase of signal, respectively.

Then, (8) and (9) can be obtained.

$$
\begin{aligned}
& a(t)=\sqrt{s(t)^{2}+s_{\mathrm{H}}(t)^{2}} \\
& \varphi(t)=\arctan \frac{s_{\mathrm{H}}(t)}{s(t)}
\end{aligned}
$$

The instantaneous frequency equation is as:

$f(t)=\frac{1}{2 \pi} \frac{\mathrm{d} \varphi(t)}{\mathrm{d} t}$

The wind power is decomposed into 11 IMFs and a residual component by EMD. Eleven IMFs including $\mathrm{c}_{11}$, $c_{10}, \ldots, c_{1}$ are arranged in ascending order of frequency. Lower frequency IMFs combined with the residual component are usually selected as grid-connected wind power to meet the grid-connected fluctuation rate constraint. The 1-min max fluctuation rate of $c_{11}-c_{7}$ IMFs combined with the residual component is 0.0261 , which is greater than 0.02 , while that of $c_{11}-c_{8}$ IMFs combined with the residual component is 0.0141 , which is significantly lower than the smoothing requirements, as

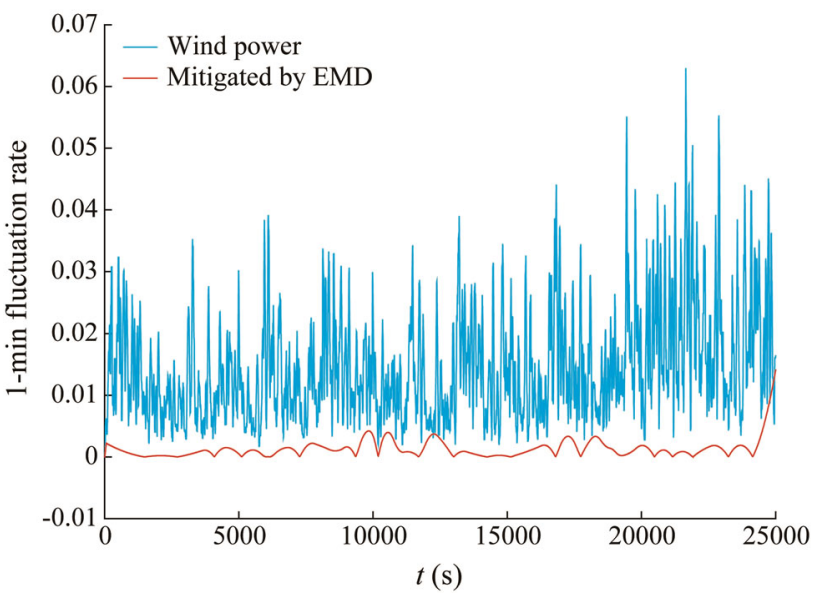

Fig. 13 Wind power fluctuation rate before and after smoothing by EMD

displayed in Fig. 13. Therefore, the $\mathrm{c}_{11}-\mathrm{c}_{8}$ IMFs combined with the residual component are used as the grid-connected wind power, as shown in Fig. 14.

\subsection{MDC algorithm}

The detailed principle of MPC is:

\section{1) Receding horizon strategy}

Receding horizon strategy is the main part of MPC. It contains the following steps: (1) considering the current and future constraints, the next control instruction sequence at time $k+1, k+2, \ldots$, and $k+M$ can be acquired based on the current time $k$ and state $x(k)$ by solving the optimization problem; (2) the first control instruction is applied to the control system, thus the state is updated to $x(k+1)$ at time $k+1$; and (3) the above steps are repeated until the operation requirements are met.

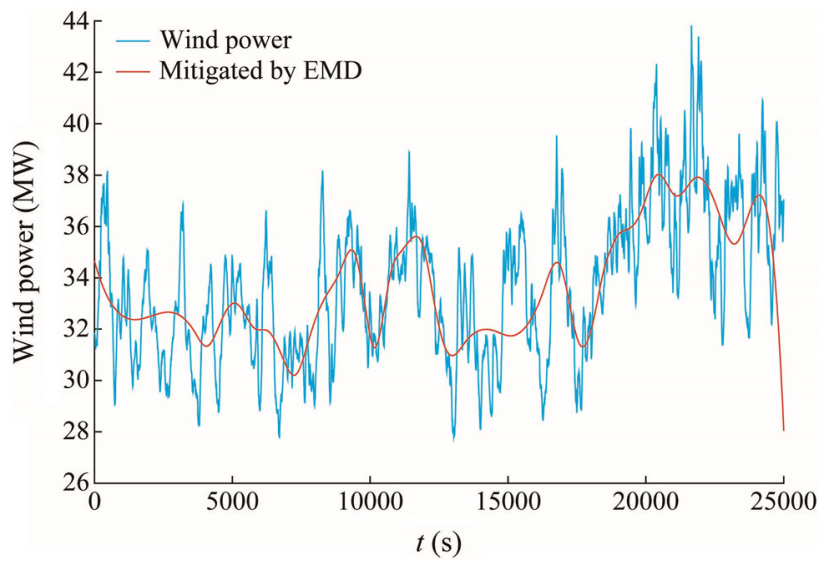

Fig. 14 Wind power before and after smoothing by EMD 
2) State space model

As for the state space theory, the state, control input, and interference input and output variables at time $k$ can be expressed as $\boldsymbol{x}(k), \boldsymbol{u}(k), \boldsymbol{r}(k)$, and $\boldsymbol{y}(k)$, respectively. Then the state space equation can be established as follows.

$\boldsymbol{x}(k+1)=\boldsymbol{A} \boldsymbol{x}(k)+\boldsymbol{B}_{1} \boldsymbol{u}(k)+\boldsymbol{B}_{2} \boldsymbol{r}(k)$

$\boldsymbol{y}(k)=\boldsymbol{C} \boldsymbol{x}(k)+\boldsymbol{D}_{1} \boldsymbol{u}(k)+\boldsymbol{D}_{2} \boldsymbol{r}(k)$

Substitute (11) into (12), and (13) can be obtained.

$$
\begin{aligned}
\boldsymbol{y}(k+1)= & \boldsymbol{C}\left(\boldsymbol{A} \boldsymbol{x}(k)+\boldsymbol{B}_{1} \boldsymbol{u}(k)+\boldsymbol{B}_{2} \boldsymbol{r}(k)\right)+\boldsymbol{D}_{1} \boldsymbol{u}(k+1) \\
& +\boldsymbol{D}_{2} \boldsymbol{r}(k+1)
\end{aligned}
$$

where $\boldsymbol{A}, \boldsymbol{B}_{1}, \boldsymbol{B}_{2}, \boldsymbol{C}, \boldsymbol{D}_{1}$, and $\boldsymbol{D}_{2}$ are the coefficient matrices.

The control instruction at time $k+M$ can be predicted by iteration of (13). The specific equation is:
Suppose the control step and ES capacity are $T_{c}$ and $C_{e s}$, respectively, and ES SOC is calculated as:

$\operatorname{SOC}(k+1)=\operatorname{SOC}(k)-T_{c} P_{e s}(k) / C_{e s}$

The objective of minimum (min) ES usage for each control step is obtained through iteration and optimization.

$J=\min \sum_{i=k}^{k+M} P_{e s}^{2}(i)$

The relevant constraints are:

$P_{g, \text { min }} \leq P_{g}(i) \leq P_{g, \max }$

$\frac{\max P_{g}(i)-\min P_{g}(i)}{P_{\text {wind,rated }}} \leq \gamma$

$P_{e s, \min } \leq P_{e s}(i) \leq P_{e s, \max }$

$0 \leq \operatorname{SOC}(i) \leq 1$

$\left[\begin{array}{c}\boldsymbol{y}(k) \\ \boldsymbol{y}(k+1) \\ \boldsymbol{y}(k+2) \\ \vdots \\ \boldsymbol{y}(k+M)\end{array}\right]=\left[\begin{array}{c}\boldsymbol{C} \\ \boldsymbol{C A} \\ \boldsymbol{C A}^{2} \\ \vdots \\ \boldsymbol{C A}^{M}\end{array}\right][\boldsymbol{x}(k)]$

$+\left[\begin{array}{cccccc}\boldsymbol{D}_{1} & \mathbf{0} & \mathbf{0} & \mathbf{0} & \cdots & \mathbf{0} \\ \boldsymbol{C B}_{1} & \boldsymbol{D}_{1} & \mathbf{0} & \mathbf{0} & \cdots & \mathbf{0} \\ \boldsymbol{C A B} \boldsymbol{B}_{1} & \boldsymbol{C B}_{1} & \boldsymbol{D}_{1} & \mathbf{0} & \cdots & \mathbf{0} \\ \vdots & \vdots & \vdots & \vdots & \vdots & \vdots \\ \boldsymbol{C A}^{M-1} \boldsymbol{B}_{1} & \boldsymbol{C A}^{M-2} \boldsymbol{B}_{1} & \boldsymbol{C A}^{M-3} \boldsymbol{B}_{1} & \cdots & \boldsymbol{C B}_{1} & \boldsymbol{D}_{1}\end{array}\right]\left[\begin{array}{c}\boldsymbol{u}(k) \\ \boldsymbol{u}(k+1) \\ \boldsymbol{u}(k+2) \\ \vdots \\ \boldsymbol{u}(k+M)\end{array}\right]$

$+\left[\begin{array}{cccccc}\boldsymbol{D}_{2} & \mathbf{0} & \mathbf{0} & \mathbf{0} & \cdots & \mathbf{0} \\ \boldsymbol{C B}_{2} & \boldsymbol{D}_{2} & \mathbf{0} & \mathbf{0} & \cdots & \mathbf{0} \\ \boldsymbol{C A B} \boldsymbol{B}_{2} & \boldsymbol{C} \boldsymbol{B}_{2} & \boldsymbol{D}_{2} & \mathbf{0} & \cdots & \mathbf{0} \\ \vdots & \vdots & \vdots & \vdots & \vdots & \vdots \\ \boldsymbol{C} \boldsymbol{A}^{M-1} \boldsymbol{B}_{2} & \boldsymbol{C A}^{M-2} \boldsymbol{B}_{2} & \boldsymbol{C A}^{M-3} \boldsymbol{B}_{2} & \cdots & \boldsymbol{C B}_{2} & \boldsymbol{D}_{2}\end{array}\right]\left[\begin{array}{c}\boldsymbol{r}(k) \\ \boldsymbol{r}(k+1) \\ \boldsymbol{r}(k+2) \\ \vdots \\ \boldsymbol{r}(k+M)\end{array}\right]$

\section{3) MPC application}

According to the receding horizon strategy, state space model, and actual demand, the ES model to smooth wind power fluctuation can be established with MPC. Then, wind power, ES power, and ES SOC at time $k$ are expressed as $P_{w}(k), P_{e s}(k)$, and $S O C(k)$. In addition, the relationships between grid-connected wind power, wind power, and ES power are characterized as:

$P_{g}(k+1)=P_{e s}(k)+P_{w}(k)$

where $P_{g}(k+1)$ is the grid-connected wind power at time $k+1$.
Equations (18) and (19) reflect the power and fluctuation rate constraints of grid-connected wind power, respectively. Equations (20) and (21) reflect the power and SOC constraints of ES, respectively.

MPC has a good tracking effect on the original wind power owing to its prediction and real-time control characteristics, as demonstrated in Fig. 15. As shown in Fig. 16, the 1-min max fluctuation rate of smoothed wind power is 0.02 .

Table 1 displays the 1-min max fluctuation rate of wind power smoothed by the above five control strategies. EMD has the smallest value, while MPC gets the largest value. In 


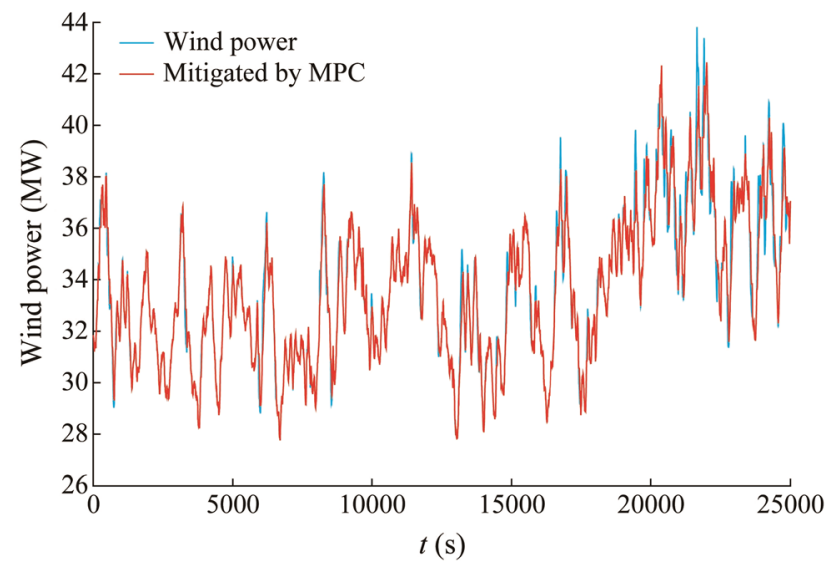

Fig. 15 Wind power before and after smoothing by MPC

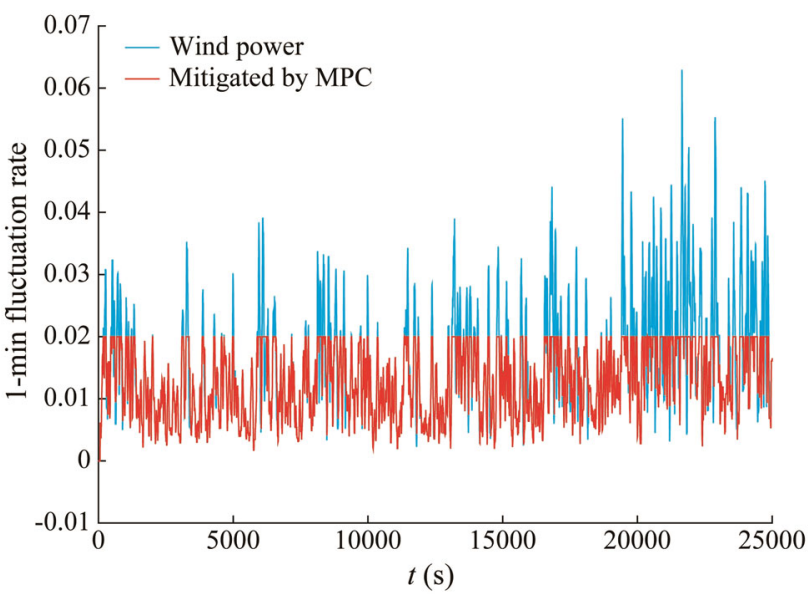

Fig. 16 Wind power fluctuation rate before and after smoothing by MPC

Table 1 Wind power fluctuation rate with different control strategies

\begin{tabular}{lll}
\hline Method & $\begin{array}{l}\text { Max fluctuation rate before } \\
\text { smoothing }\end{array}$ & $\begin{array}{l}\text { Max fluctuation rate after } \\
\text { smoothing }\end{array}$ \\
\hline CLF & 0.0630 & 0.0180 \\
VLF & 0.0630 & 0.0199 \\
WPD & 0.0630 & 0.0154 \\
EMD & 0.0630 & 0.0141 \\
MPC & 0.0630 & 0.0200
\end{tabular}

general, the smaller the smoothed wind power fluctuation rate, the more ES capacity needed to stabilize power fluctuation.

\subsection{ES sizes with different control strategies}

The ES power curves can be obtained through the above five control strategies with the same grid-connected fluctuation rate constraints. The details are displayed in

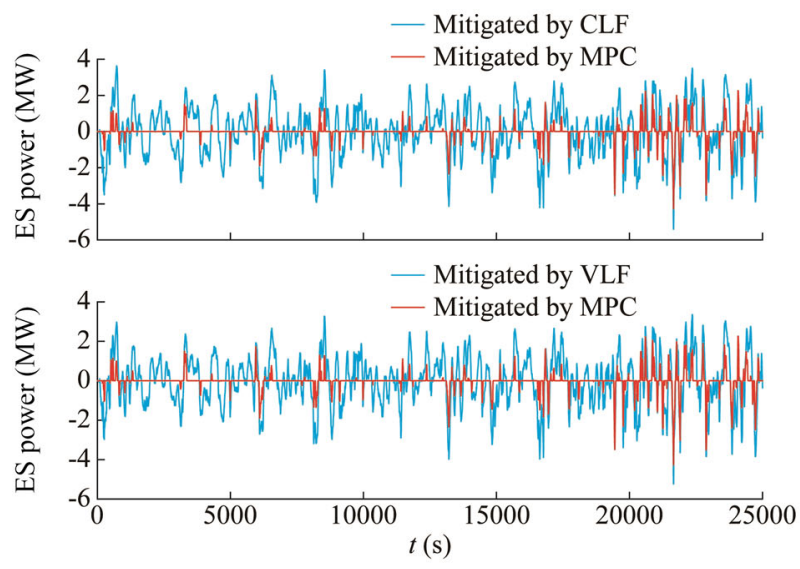

(a)

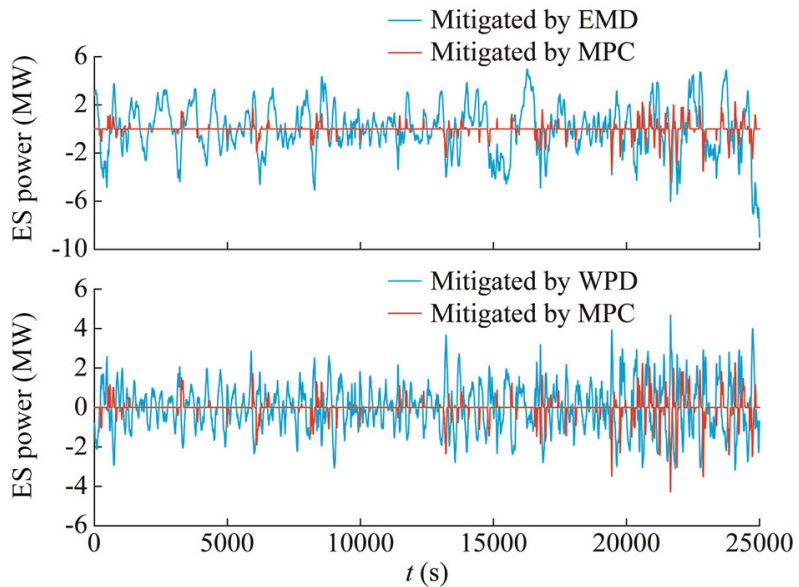

(b)

Fig. 17 ES power with different control strategies

Table 2 ES sizes with different control strategies

\begin{tabular}{lll}
\hline Methods & $\begin{array}{l}\text { Max charge and discharge power } \\
(\mathrm{MW})\end{array}$ & $\begin{array}{l}\text { Capacity } \\
(\mathrm{MWh})\end{array}$ \\
\hline CLF & 5.4371 & 0.4286 \\
VLF & 5.2688 & 0.3790 \\
WPD & 4.7085 & 0.3160 \\
EMD & 8.9724 & 0.8662 \\
MPC & 4.2978 & 0.2662 \\
\hline
\end{tabular}

Fig. 17. ES max charge and discharge power of MPC are smaller than those of the other four control strategies. In addition, there are more zero points in the ES power of MPC, which means ES is used less.

For Table 2, ES sizes including max charge and discharge power, and capacity in ascending order are as follows: $\mathrm{MPC}<\mathrm{WPD}<\mathrm{VLF}<\mathrm{CLF}<\mathrm{EMD}$, which are calculated by (22) and (23). Therefore, the ES sizes of MPC are minimal, that is, MPC is the optimal control strategy. 
Table 3 Cut-off frequency with different control strategies

\begin{tabular}{ll}
\hline Method & Cut-off frequency $(\mathrm{Hz})$ \\
\hline CLF & $1.22 \times 10^{-3}$ \\
VLF & $1.34 \times 10^{-3}$ to $1.77 \times 10^{-3}$ \\
WPD & $1.56 \times 10^{-3}$ \\
EMD & $0.97 \times 10^{-3}$ \\
MPC & $8.65 \times 10^{-3}$
\end{tabular}

The ES max charge and discharge power can be obtained as:

$P_{m}=\max \left(\left|P_{e s}(k)\right|\right)$

ES capacity can be calculated as:

$C_{e s}=\max (E(k))-\min (E(k))$

$E(k)=\int_{0}^{T} P_{e s}(k) \mathrm{d} t$

where $E$ is the change in energy, and it can be obtained by the integrating power with respect to time.

In addition, the reasons for different ES sizes under different control strategies are analyzed from the viewpoint of smoothed cut-off frequency. The time constant in CLF is $130 \mathrm{~s}$, and the cut-off frequency of $1.22 \times 10^{-3} \mathrm{~Hz}$ can be calculated according to $\tau=1 /(2 \pi f)$. The time constant range in VLF is from $90 \mathrm{~s}$ to $119.1 \mathrm{~s}$, and the calculated cut-off frequency is from $1.34 \times 10^{-3}$ to $1.77 \times 10^{-3} \mathrm{~Hz}$. The cut-off frequency of $1.56 \times 10^{-3} \mathrm{~Hz}$ in WPD can be obtained by (4). The max instantaneous frequency of $0.97 \times 10^{-3} \mathrm{~Hz}$ in EMD can be acquired by the decomposition and HHT of grid-connected wind power. Similarly, the max instantaneous frequency of $8.65 \times 10^{-3} \mathrm{~Hz}$ in MPC can also be acquired.

Tables 2 and 3 show that the cut-off frequency is negatively related to the ES size. The smaller the cut-off frequency, the greater the size of the needed ES. Owing to model prediction and advance control of MPC, the wind power fluctuation rate, which is greater than 0.02 , will be exactly 0.02 after smoothing. In this scenario, wind power will not be over-suppressed, and ES size can be saved. Therefore, MPC has the widest cut-off frequency, and the min ES size is required.

\section{Power allocation between hybrid ES}

\subsection{Allocation strategies}

Recently, the low-pass filtering algorithm has been used to achieve the power allocationin between hybrid ES [23-25]. However, the determination of the filter time constant is less studied. In addition, when the traditional low-pass filtering algorithm (TLFA) is used to achieve power distribution in hybrid ES, the opposite charge and discharge statuses for LB and SC will appear. When LB charges, SC discharges. Conversely, when LB discharges, $\mathrm{SC}$ charges. This will lead to power flow between the LB and SC, and the energy loss will increase. Therefore, an ILFA is proposed to improve the operation efficiency of hybrid ES.

Firstly, the mean frequency of the ES, as the cut-off frequency of the low-pass filtering algorithm, is obtained by HHT in this section. Furthermore, the filter time constant can also be calculated.

Secondly, for the ILFA, when the LB and SC have different charge and discharge statuses, the LB power proportion in the hybrid ES will be recalculated through (25). Therefore, the LB power has the same charge and discharge status as ES, which will be obtained. The rest of the ES power is compensated by the SC with the same charge and discharge status, as shown in (26). Hence, the LB and SC will have synchronous charge and discharge statuses, and the power distribution characteristics of the low-pass filtering algorithm will also be preserved.

$P_{l i, r}=P_{e s} \frac{\left|P_{l i}\right|}{\left|P_{l i}\right|+\left|P_{s c}\right|}$

$P_{s c, r}=P_{e s}-P_{l i, r}$

where $P_{l i}$ and $P_{s c}$ are the LB and SC power; $P_{l i, r}$ and $P_{s c, r}$ are the improved LB and SC power. A positive value represents discharge, and a negative value describes charge.

Furthermore, as the SC has a longer cycle life and a more rapid response, the preferred SC charging and discharging strategy based on the FC method is used to

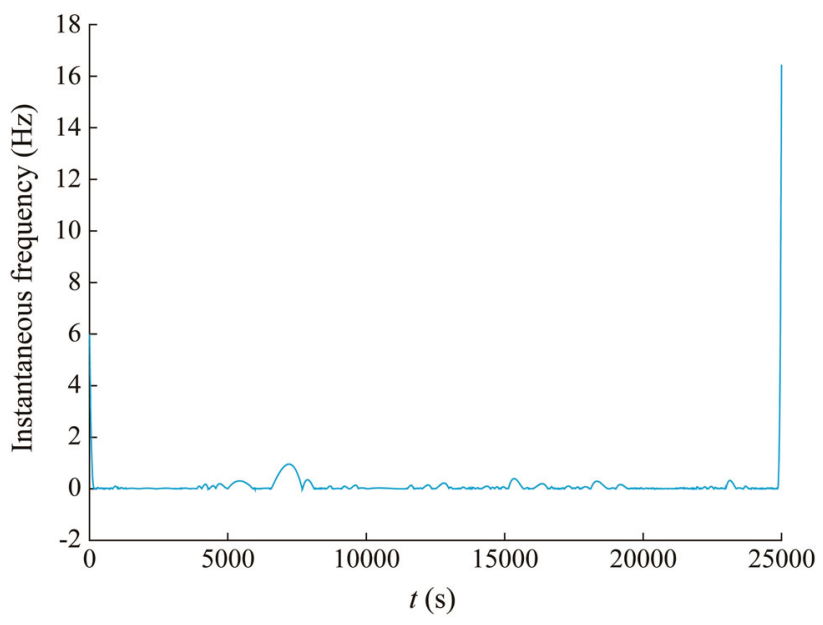

Fig. 18 Instantaneous frequency of ES 


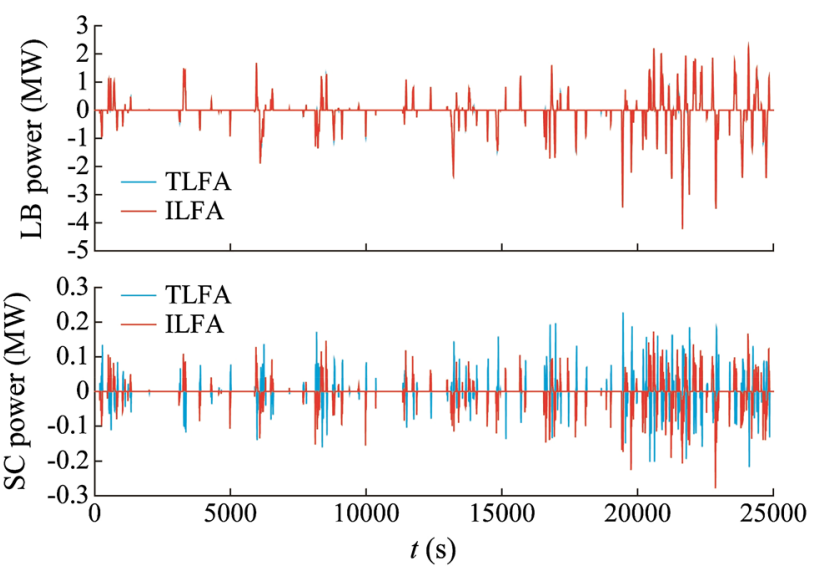

Fig. 19 LB and SC power in TLFA and ILFA

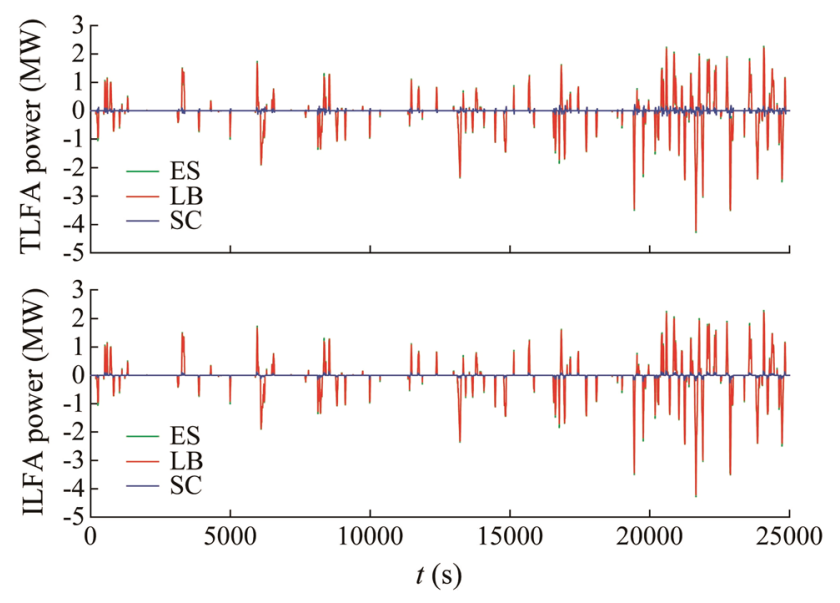

Fig. 20 ES, LB, and SC power in TLFA and ILFA

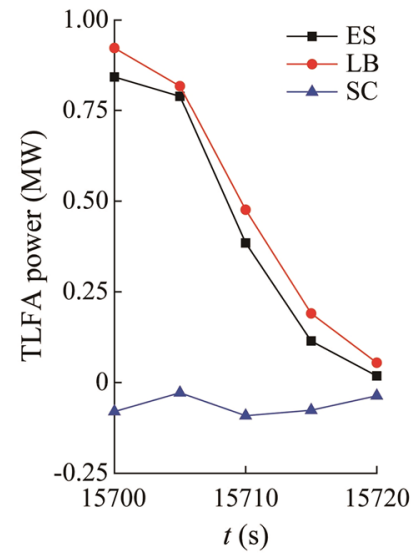

(a)

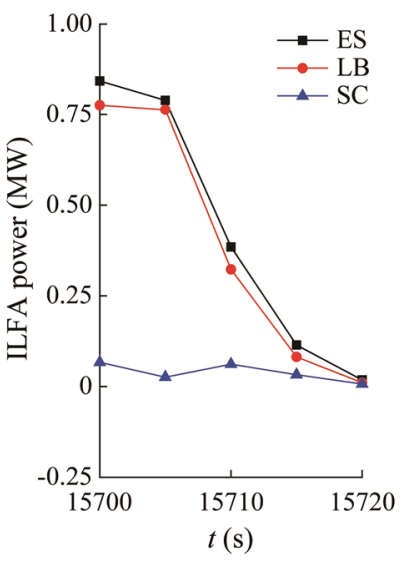

(b)
Fig. 21 Details of ES, LB, and SC power in TLFA and ILFA (from $15700 \mathrm{~s}$ to $15720 \mathrm{~s}$ )

optimize the operation of hybrid ES. Therefore, the efficiency and cycle life of the hybrid ES will be improved greatly through the proposed control strategies.

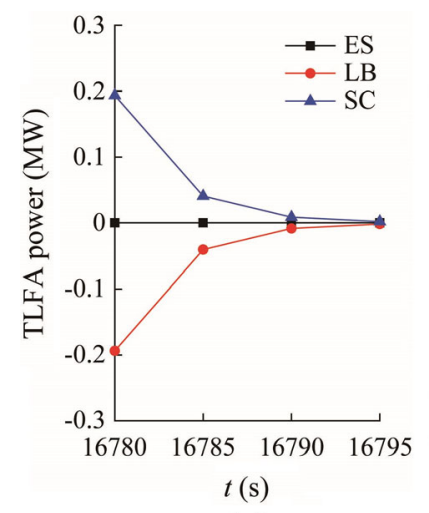

(a)

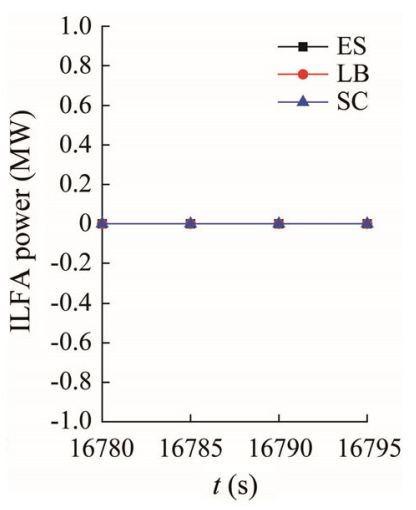

(b)
Fig. 22 Details of ES, LB, and SC power in TLFA and ILFA (from $16780 \mathrm{~s}$ to $16795 \mathrm{~s}$ )

\subsection{Case study}

\section{1) ILFA}

The frequency of ES power is obtained by HHT, as shown in Fig. 18. The average frequency is $0.1194 \mathrm{~Hz}$, and the corresponding filter time constant is $1.333 \mathrm{~s}$.

The LB and SC power can be acquired by ILFA and TLFA, as displayed in Fig. 19.

In order to better illustrate the advantages of ILFA, ES, LB and SC power in TLFA and ILFA are described in Fig. 20. Some of the power details of Fig. 20 are given in Figs. 21 and 22. The power curves of ILFA and TLFA from $15700 \mathrm{~s}$ to $15720 \mathrm{~s}$ are shown in Fig. 21. In TLFA, when the ES power is positive, the LB power is positive, while the SC power is negative. That is, the LB and SC have different charge and discharge conditions. In addition, the LB discharge power is always greater than that of ES. At this point, the LB discharge power and the energy consumption in hybrid ES are greatly increased.

As shown in Fig. 22a, when ES power is 0, the output power values of LB and SC are contradictory. In this case, the usages of the LB and SC are increased, and their cycle lives are reduced.

From Figs. 21b and 22b, the LB and SC have the same charge and discharge status as ES, and the LB discharge power is always smaller than that of ES. When the ES power is 0 , the LB and SC power are also 0 . This will not increase the usage of hybrid ES. Hence, the technological economy of hybrid ES can be improved with ILFA.

\section{2) SC preferred FC-based method}

Based on ILFA, hybrid ES power is further optimized with a FC-based method considering SC SOC. SC SOC can be maintained in a reasonable state to deal with the next charge and discharge instructions. The advantages of the 


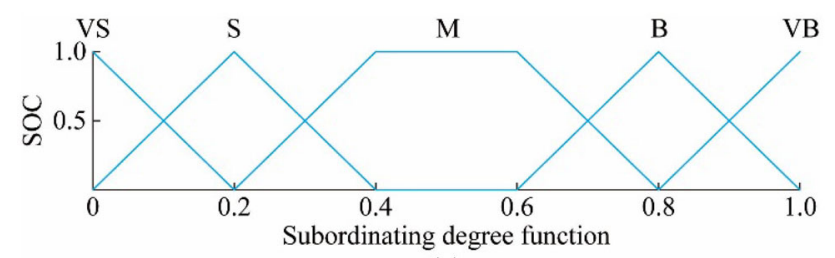

(a)

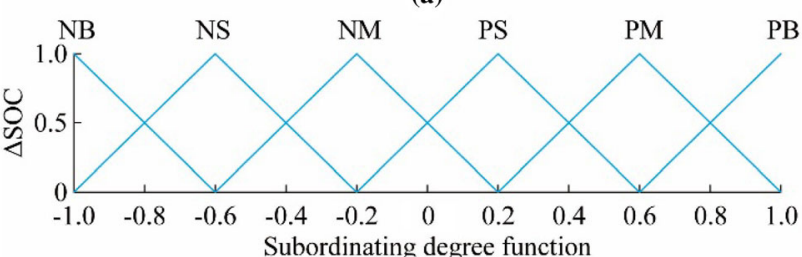

(b)

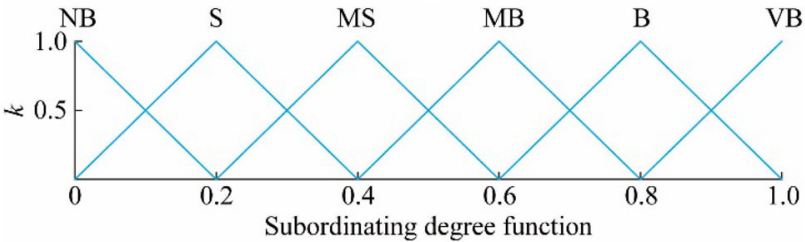

(c)

Fig. 23 Input and output variable subordinating degree functions

Table 4 Rule of FC

\begin{tabular}{|c|c|c|c|c|c|c|}
\hline \multirow[t]{2}{*}{ Fuzzy set of SOC } & \multicolumn{6}{|c|}{$\triangle S O C$} \\
\hline & $\mathrm{NB}$ & $\mathrm{NM}$ & NS & PS & PM & $\mathrm{PB}$ \\
\hline VS & VS & VS & VS & VB & VB & VB \\
\hline$S$ & $\mathrm{~S}$ & MB & $\mathrm{B}$ & VB & VB & MB \\
\hline M & MS & $\mathrm{B}$ & VB & VB & MB & MS \\
\hline B & MB & VB & VB & B & MB & S \\
\hline VB & VB & VB & VB & VS & VS & VS \\
\hline
\end{tabular}

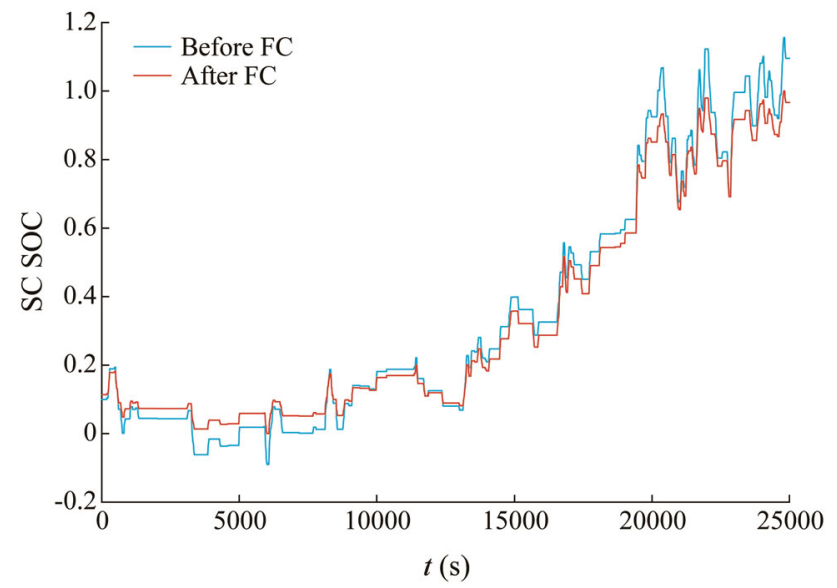

Fig. 24 SC SOC before and after FC

SC including longer cycle life and rapid response can be displayed. The optimized LB power can be also obtained. The details are as follows.

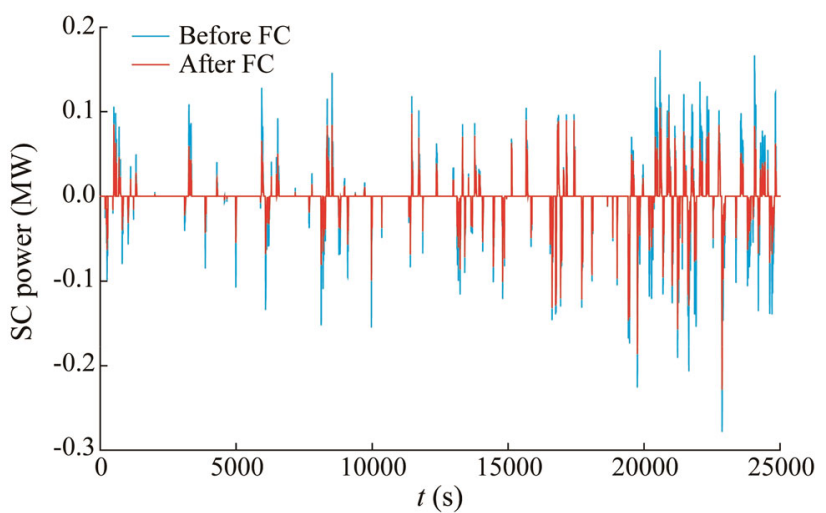

Fig. 25 SC power before and after FC

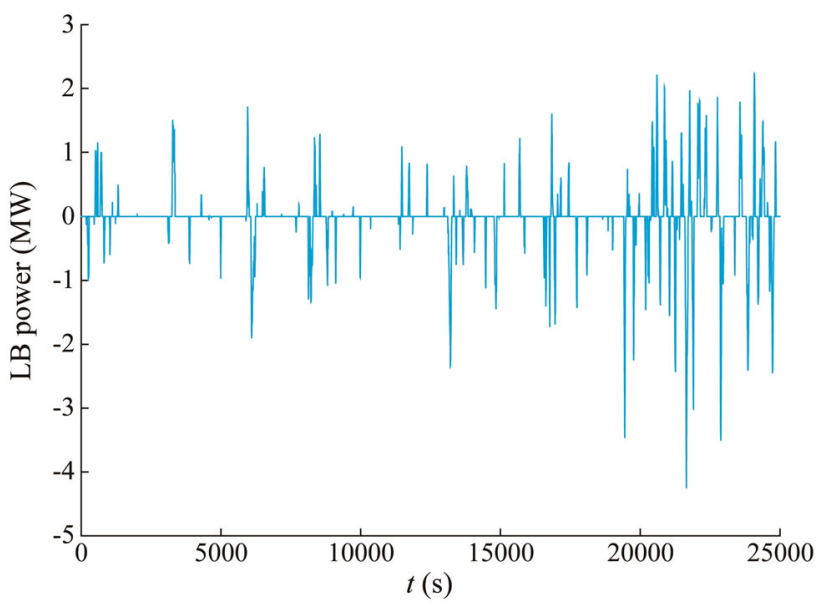

Fig. 26 LB power

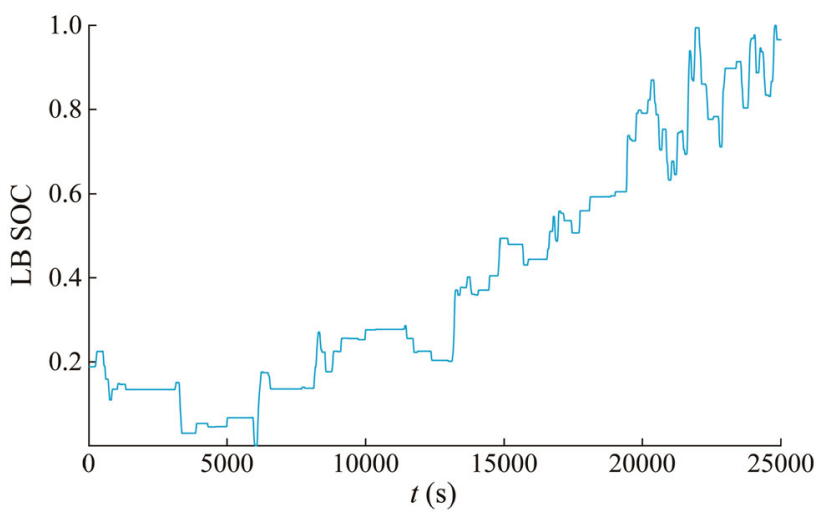

Fig. 27 LB SOC

1) When SOC is moderate, the SC charges or discharges according to the instructions.

2) When the $\mathrm{SC}$ is ready to discharge with a smaller SOC or charge with a larger SOC, the SOC will be modified based on FC and the correction factor $k$ can be obtained. The corrected SC power is calculated by 
$P_{s c, f c}=k P_{s c, r}$. The difference between $P_{s c, f c}$ and $P_{s c, r}$ will be compensated by the LB.

The current value of SOC and the variation $\triangle S O C$ at the next moment of the SC are used as the input variables of FC. The correction factor $k$ is described as the output variable. The input and output variable subordinating degree functions are introduced in Fig. 23. The fuzzy set of the input variable $\mathrm{SOC}$ is $\{\mathrm{VS}, \mathrm{S}, \mathrm{M}, \mathrm{B}, \mathrm{VB}\}$, and the domain is $[0,1]$. The fuzzy set of input variable $\triangle S O C$ is $\{\mathrm{NB}, \mathrm{NM}, \mathrm{NS}, \mathrm{PS}, \mathrm{PM}, \mathrm{PB}\}$, and the domain is $[-1,1]$. The fuzzy set of the output variable $k$ is \{VS, S, MS, MB, $\mathrm{B}, \mathrm{VB}\}$, and the domain is $[0,1]$. The fuzzy rules are displayed in Table 4.

When the capacity of SC is $0.01 \mathrm{MWh}$, its SOC, which ranges from -0.0896 to 1.1560 , is out of the desired range. It can then operate in the normal range of 0-1 using FC, as shown in Fig. 24.

The SC power values before and after FC are shown in Fig. 25. The former max charge and discharge power of $0.2284 \mathrm{MW}$ is smaller than the latter 0.2785 MW. Therefore the SC preferred charging and discharging strategy with FC is effective. The LB power is obtained in Fig. 26. Its max charge and discharge power and min capacity are $4.2573 \mathrm{MW}$ and $0.2571 \mathrm{MWh}$, which can be obtained by (22) and (23). The SOC from 0 to 1 , which is calculated by (16), is displayed in Fig. 27. Therefore, LB operates in a normal range.

\section{Conclusion}

In this study, wind power fluctuation smoothing strategy and hybrid ES power distribution strategy are mainly studied.

1) CLF, VLF, WPD, EMD, and MPC are used to mitigate wind power fluctuation under the same constrains. MPC has the advantages of early prediction and timely control. The smoothed cut-off frequency of MPC is the widest, and the over-suppressed wind power will not appear. Then the max charge and discharge power, and the capacity of ES can be saved.

2) The average frequency of ES power as the time constant in ILFA is obtained by HHT. Then ILFA is applied to achieve the power allocation between the LB and SC to overcome the overuse and internal energy consumption of hybrid ES. Furthermore, preferential use control strategy of the SC based on FC is established considering its SOC, and optimized LB and SC power can be obtained.

Therefore, hybrid ES is used to stabilize wind power fluctuation, which can greatly promote the large-scale development of renewable energy sources, and the popularization of ES in renewable energy sources. In the future, the application of ES in a demand side response will be studied, whose technical economy will be analyzed and the potential profit will be explored.

Acknowledgements This work was supported by National Key Research and Development Program of China (No. 2016YFB0900400), Foundation of Director of Institute of Electrical Engineering, Chinese Academy of Sciences (No. Y760141CSA), and Jiangsu Province 2016 Innovation Ability Construction Special Funds (No. BM2016027).

Open Access This article is distributed under the terms of the Creative Commons Attribution 4.0 International License (http:// creativecommons.org/licenses/by/4.0/), which permits unrestricted use, distribution, and reproduction in any medium, provided you give appropriate credit to the original author(s) and the source, provide a link to the Creative Commons license, and indicate if changes were made.

\section{References}

[1] Luo JQ, Shi LB, Ni YX (2018) A solution of optimal power flow incorporating wind generation and power grid uncertainties. IEEE Access 6:19681-19690

[2] Tajdinian M, Seifi AR, Allahbakhshi M (2018) Sensitivitybased approach for real-time evaluation of transient stability of wind turbines interconnected to power grids. IET Renew Power Gener 12(6):668-679

[3] Sun YS, Tang XS (2014) Cascading failure analysis of power flow on wind power based on complex network theory. J Mod Power Syst Clean Energy 2(4):411-421

[4] Pouresmaeil E, Mehrasa M, Shokridehaki MA et al (2015) Control of modular multilevel converters for integration of distributed generation sources into the power grid. In: Proceedings of the 2015 IEEE international conference on smart energy grid engineering, Oshawa, Canada, 17-19 August 2015, $6 \mathrm{pp}$

[5] Pouresmaeil E, Mehrasa M, Godina R et al (2017) Double synchronous controller for integration of large-scale renewable energy sources into a low-inertia power grid. In: Proceedings of the 2017 IEEE PES innovative smart grid technologies conference Europe, Torino, Italy, 26-29 September 2017, 6 pp

[6] Mehrasa M, Rezanejhad M, Pouresmaeil E et al (2016) Analysis and control of single-phase converters for integration of smallscaled renewable energy sources into the power grid. In: Proceedings of the 20167 th power electronics and drive systems technologies conference, Tehran, Iran, 16-18 February 2016, 6 $\mathrm{pp}$

[7] Mehrasa M, Godina R, Pouresmaeil E et al (2017) Synchronous active proportional resonant-based control technique for high penetration of distributed generation units into power grids. In: Proceedings of the 2017 IEEE PES innovative smart grid technologies conference Europe, Torino, Italy, 26-29 September 2017, 6pp

[8] Krata J, Saha TK (2018) Real-time coordinated voltage support with battery energy storage in a distribution grid equipped with medium-scale PV generation. IEEE Trans Smart Grid. https:// doi.org/10.1109/tsg.2018.2828991 
[9] Okedu KE (2017) Effect of ECS low-pass filter timing on grid frequency dynamics of a power network considering wind energy penetration. IET Renew Power Gener 11(9):1194-1199

[10] Zhang DL, Guo JB, Li JL (2017) Coordinated control strategy of hybrid energy storage to improve accommodating ability of PV. J Eng 13:1555-1559

[11] Escalera A, Hayes B, Prodanovic M (2017) Analytical method to assess the impact of distributed generation and energy storage on reliability of supply. In: Proceedings of CIRED 2017 24th international conference on electricity distribution, Glasgow, UK, 12-15 June 2017, 6 pp

[12] Chong LW, Wong YW, Rajkumar RK et al (2016) An optimal control strategy for standalone PV system with battery-supercapacitor hybrid energy storage system. J Power Sour 331:553-565

[13] Abbassi A, Dami MA, Jemli M (2017) Statistical characterization of capacity of hybrid energy storage system (HESS) to assimilate the fast PV-wind power generation fluctuations. In: Proceedings of the 2017 international conference on advanced systems and electric technologies, Hammamet, Tunisia, 14-17 January 2017, pp 467-472

[14] Haque ME, Khan MNS, Sheikh MRI (2015) Smoothing control of wind farm output fluctuations by proposed low pass filter, and moving averages. In: Proceedings of the 2015 international conference on electrical and electronic engineering, Rajshahi, Bangladesh, 4-6 November 2015, pp 121-124

[15] Sun YS, Tang XS, Zhang GW et al (2017) Dynamic power flow cascading failure analysis of wind power integration with complex network theory. Energies 11(1):1-15

[16] Jiang QY, Wang HJ (2013) Two-time-scale coordination control for a battery energy storage system to mitigate wind power fluctuations. IEEE Trans Energy Convers 28(1):52-61

[17] Christian SN, Liu KZ (2016) Online wavelet based control of hybrid energy storage systems for smoothing wind farm output. In: Proceedings of the IECON 2016 42nd annual conference of the IEEE industrial electronics society, Florence, Italy, 23-26 October 2016, 6 pp

[18] Wang YF, Li MM, Xue $\mathrm{H}$ et al (2017) PV power smoothing in regional grid based on self-adaption wavelet packet decomposition. In: Proceedings of the 2017 IEEE conference on energy internet and energy system integration, Beijing, China, 26-28 November 2017, 6 pp

[19] Jiang QY, Hong HS (2013) Wavelet-based capacity configuration and coordinated control of hybrid energy storage system for smoothing out wind power fluctuations. IEEE Trans Power Syst 28(2):1363-1372

[20] Yuan Y, Sun CC, Li MT et al (2015) Determination of optimal SC-lead-acid battery energy storage capacity for smoothing wind power using empirical mode decomposition and neural network. Electric Power Syst Res 127:323-331

[21] Lin XD, Lei Y (2017) Coordinated control strategies for smesbattery hybrid energy storage systems. IEEE Access 5:23452-23465

[22] Yang XY, Cao C, Li XJ et al (2015) Control method of smoothing wind power output using battery energy storage system based on empirical mode decomposition. In: Proceedings of the 2015 34th Chinese control conference, Hangzhou, China, 28-30 July 2015, 5 pp
[23] Tang XS, Sun YS, Zhou GP et al (2017) Coordinated control of multi-type energy storage for wind power fluctuation suppression. Energies 10(8):1-16

[24] Pang M, Shi YK, Wang WD et al (2016) A method for optimal sizing hybrid energy storage system for smoothing fluctuations of wind power. In: Proceedings of the 2016 IEEE PES AsiaPacific power and energy engineering conference, $\mathrm{Xi}$ ' an, China, 25-28 October 2016, 4 pp

[25] Bai LQ, Li FX, Hu QR et al (2016) Application of batterysupercapacitor energy storage system for smoothing wind power output: an optimal coordinated control strategy. In: Proceedings of the 2016 PES general meeting, Boston, USA, 17-21 July 2016, 5 pp

Yushu SUN received the M.S. degree from North China electric power university (NCEPU), Beijing, China, in 2013. He works as a research assistant at the Institute of Electrical Engineering of Chinese Academy of Sciences since 2013. His research interests include renewable energy, power generation, energy storage and microgrid.

Xisheng TANG received the Ph.D. degree from the Institute of Electrical Engineering of Chinese Academy of Sciences, Beijing, China, in 2006. He is currently a professor at the Institute of Electrical Engineering of Chinese Academy of Sciences. His research interests include power system stability and control, distributed generation and energy storage technologies, application of power electronics in power system.

Xiaozhe SUN received the M.S. degree from Northeast Petroleum University, Daqing, China, in 2016. He works as an engineer at Sinopec Oilfield Service Shengli Corporation Tarim Branch Company since 2009. His research interests include renewable energy generation and synthetic utilization of multi fossil fuels.

Dongqiang JIA received the Ph.D. degree in power system automation from the Institute of Electrical Engineering of Chinese Academy of Sciences, Beijing, China, in 2015. He is currently an engineer at State Grid Beijing Electric Power Company Electric Power Research Institute. His research interests include system operation control and power quality.

Zhihuang CAO is currently a professor-level senior engineer at State Grid Anhui Electric Power Company. His research interests include high voltage, power grid regulation and operation.

Jing PAN is currently a senior engineer at State Grid Anhui Electric Power Company. Her research interests include power system information technology, new energy and energy storage technology.

Bin XU is currently a senior engineer at State Grid Anhui Electric Power Company. Her research interests include power quality and new energy. 